\title{
Lingkungan dan Pembelajaran Bahasa Indonesia
}

\author{
Oleh: Silta Yulia/18016185 \\ Siltayulia6153@gmail.com
}

Kerusakan lingkungan menjadi salah satu permasalahan besar yang tidak hanya terjadi di Indonesia, namun menjadi permasalahan besar yang dihadapi dunia. Seluruh negara di dunia merasakan dampak buruk yang disebabkan oleh kerusakan lingkungan yang terjadi karena ulah manusia yang serakah dan tidak bertanggung jawab. Menurut Mitsuki dan Lai (dalam Ramadhan et al, 2019), di seluruh dunia, setiap orang menghadapi masalah lingkungan yang serius, seperti pemanasan global, hujan asam, perusakan lapisan ozon, pencemaran lingkungan, kerusakan alam, dan hilangnya keragaman hayati dapat mengancam kehidupan generasi mendatang. Masalah lingkungan disebabkan oleh aktivitas manusia yang ceroboh dan intensif di daerah alami untuk meningkatkan kualitas kehidupan mereka. Aspek yang lebih mengancam adalah ketidaksadaran pengaruh manusia terhadap lingkungan mereka. Kerusakan lingkungan menghasilkan krisis ekologis yang akan menyebabkan serangkaian masalah dengan sumber daya alam, iklim, polusi, makanan dan ekonomi.

Pendidikan lingkungan dapat dianggap sebagai kunci karena mendorong individu untuk melindungi lingkungan dari potensi lokal dan yang ada tantangan lingkungan global (Sukma, Ramadhan dan Indriyani, 2020). Sejalan dengan hal itu, Amalia, Sukma dan Asma (2015) dalam penelitiannya yang berjudul "Pembelajaran Menulis Laporan Percobaan dengan Pendekatan Saintifik di Sekolah Dasar" menyimpulkan bahwa memotivasi siswa untuk belajar menulis secara nyata karena mengumpulkan sendiri data dari objek atau fenomena percobaan yang akan ditulis laporannya, siswa merasa tertantang mengeksplorasi rasa keingintahuannya tentang fenomena alam, menyenangkan siswa karena mereka merasa bangga dapat berperan serta dalam aktivitas menulis, dan membangkitkan minat menulis siswa karena dapat mempublikasikan hasil percobaannya dalam bentuk tulisan. Untuk itu, perlu adanya pendidikan mengenai pentingnya menjaga lingkungan agar tidak rusak dan punah. Hal ini dapat kita jadikan topik dalam pembelajaran bahasa Indonesia. 
Sukma dan Indriyani (2019) yang menjelaskan bahwa tingkat pengetahuan dan kesadaran siswa terhadap lingkungan masih rendah sehingga guru perlu meningkatkan pengetahuan tentang lingkungan dan mitigasi bencana agar dapat merancang pembelajaran bahasa dengan pendidikan lingkungan dan mitigasi bencana. Sejalan dengan hal tersebut, Sari, Ramadhan dan Rasyid (2018) menyatakan bahwa guru adalah komponen yang sangat menentukan dlam implementasi suatu strategi dalam mengefektifkan proses pembelajaran.

Selain itu, Buldur dan Omeroglu (dalam Ramadhan et al, 2019), juga berpendapat bahwa pendidikan lingkungan penting untuk meningkatkan sikap dan kesadaran siswa terhadap lingkungan. Pendidikan lingkungan harus dirancang untuk berkontribusi dengan pada pengembangan kognitif, emosional, linguistik dan psikomotor siswa siswa, dan memungkinkan mereka untuk memgembangkan sikap posif terhadap lingkungan. Selain itu, guru juga harus mampu mengembangkan kemmapuan siswa untuk memahami, mengkritik, dan berpartisipasi secara rasional dalam setiap wacana tentang masalah lingkungan.

Menurut Nazarenko dan Bergman (dalam Ramadhan et al, 2019) guru memainkan peran-peran penting dalam mengajar pendidikan lingkungan dan menimbulkan kesadaarn siswa tentang lingkungan. Menurut Hauchild, Poltavhenko dan Stoller (dalam Ramadhan et al, 2019) juga menyatakan bahwa guru bahasa berada dalam posisi unik untuk mempromosikan kesadaran terhadap lingkungan.

Jika dihubungkan dengan bahasa Indonesia, maka topik tentang lingkungan bisa dimasukkan ke dalam pembelajaran bahasa Indonesia berupa teks, hal ini dikarenakan topik tersebut juga dapat digabungkan ke dalam mata pelajaran lainnya (Ramadhan et al, 2019). Rivers (dalam Ramadhan et al, 2019) juga mengatakan bahwa sebagai guru bahasa, kami adalah guru yang paling beruntung, semua mata pelajaran adalah milik kami. Apapun yang ingin dikomunikasikan oleh siswa, apapun yang ingin mereka baca merupakan materi pelajaran kami. Jadi, bahsa Indonesia merupakan mata pelajaran yang sangat penting untuk dikuasai.

Data pada tulisan ini berasal dari penyebaran angket melaui watsapp yang berisi sepuluh pernyataan dengan opsi sangat setuju, setuju, kurang setuju dan tidak setuju. Tema dari angket tersebut adalah Kaitan Pembelajaran Bahasa Indonesia dengan Lingkungan yang diberikan kepada 40 responden yang terdiri 
dari $62,5 \%$ perempuan dan 37,5\% laki-laki dan 95\% mahasiswa, 2,5\% guru serta 2,5\% pelajar. Responden dari penelitian ini terdiri dari beberapa universitas dan sekolah seperti UNAND, UNP, STKIP PGRI, Taman Siswa, UNNES, Stikes Indonesia, UPI YPTK, UIN Imam Bonjol, STMIK Akakom Yogyakarta, SMKN 9 Padang, STIKes Mercubaktijaya Padang, UBH. Hasil penelitiannya adalah sebagai berikut.

Pertama, materi tentang lingkungan penting dalam pembelajaran bahasa Indonesia. 52,5\% menyatakan sangat setuju, 47,25\% menyatakan setuju, $0 \%$ kurang setuju dan $0 \%$ menyatakan tidak setuju.

Kedua, proses daur ulang barang bekas menjadi barang yang bermanfaat dapat dijadikan sebuah teks prosedur. 55\% menyatakan setuju, 45\% menyatakan sangat setuju, $0 \%$ menyatakan kurang setuju dan $0 \%$ menyatakan tidak setuju.

Ketiga, materi lingkungan sangat erat hubungannya dengan kehidupan sehari-hari. 57,5\% menyatakan sangat setuju, 42,5\% menyatakan setuju, $0 \%$ menyatakan kurang setuju dan $0 \%$ menyatakan tidak setuju.

Keempat, salah satu faktor eksternal yang mempengaruhi hasil belajar siswa adalah lingkungan. 50\% menyatakan setuju, 45\% menyatakan sangat setuju, 5\% menyatakan kurang setuju dan $0 \%$ menyatakan tidak setuju.

Kelima, pembelajaran bahasa Indonesia dapat meningkatkan keterampilan berkomunikasi siswa di lingkungan sosial. 65\% menyatakan sangat setuju, 32,5\% menyatakan setuju, 2,5\% kurang setuju dan $0 \%$ menyatakan tidak setuju.

Keenam, upaya untuk menjaga kebersihan lingkungan dapat dilakukan dalam proses pembelajaran bahasa Indonesia. 55\% menyatakan setuju, 35\% menyatakan sangat setuju, 7,5\% menyatakan kurang setuju dan 2,5\% menyatakan tidak setuju.

Ketujuh, kosakata yang dikuasai oleh siswa didapat dari lingkungan sekitar. $60 \%$ menyatakan setuju, 30\% menyatakan sangat setuju, 10\% menyatakan kurang setuju dan $0 \%$ menyatakan tidak setuju.

Kedelapan, berdasarkan pengalaman yang didapatkan dari lingkungan melalui panca indera, siswa dapat membuat cerpen. $65 \%$ menyatakan setuju, $25 \%$ menyatakan sangat setuju, $10 \%$ menyatakan kurang setuju dan $0 \%$ menyatakan tidak setuju.

Kesembilan, lingkungan dapat mengembangkan imajinasi siswa dalam pembelajaran bahasa Indonesia. 55\% menyatakan setuju, 40\% menyatakan sangat setuju, 5\% menyatakan kurang setuju dan $0 \%$ menyatakan tidak setuju. 
Kesepuluh, pembelajaran bahasa Indonesia tentang lingkungan secara langsung atau tidak langsung menumbuhkan kepedulian siswa terhadap lingkungan. 55\% menyatakan setuju, 35\% menyatakan sangat setuju, 7,5\% menyatakan kurang setuju dan 2,5\% menyatakan tidak setuju.

Dari hasil penelitian yang dilakukan melalui pengisian angket yang disebarkan melalui watsapp dapat disimpulkan bahwa banyak siswa, mahasiswa dan juga guru setuju bahkan sangat setuju untuk memasukkan materi tentang lingkungan ke dalam pembelajaran bahasa Indonesia. Melalui pembelajaran bahasa Indonesia yang bertemakan lingkungan, sedikit banyaknya siswa termotivasi untuk mengenal dan menjaga lingkungan sekitar agar tidak rusak dan tercemar. 


\section{Daftar Pustaka}

Amin, Irzal, Syahrul R, dan Ermanto. (2013). CERITA PENAMAAN DESA DI KERINCI: Kategori dan Fungsi Sosial Teks. Jurnal Bahasa, Sastra dan Pembelajarannya

Amelia, Rizky, Elvia Sukma dan Nur Asma. (2015). Pembelajaran menulis Laporan dengan Pendekatan Saintifik di Sekolah Dasar. Prosiding Seminar Nasional Jurusan PGSD UNP. Vol. 1, No. 1

Fitri, Margian Mulya, Syahrul R., Afnita. (2018). Pengaruh Model Discovery Learning Berbantuan Media Gambar Berseri Terhadap Keterampilan Menulis Teks Eksplanasi Siswa Kelas VIII SMP Negeri 25 Padang. Jurnal Pendidikan Bahasa dan Sastra Indonesia, Vol. 1 No. 7

Indriyani, Vivi, M. Zaim, Atmazaki, dan Syahrul Ramadhan (2019). Literasi Baca Tulis dan Inovasi Kurikulum Bahasa. KEMBARA: Jurnal Keilmuan Bahasa, Sastra dan Pengajarannya. Vol. 5, No, 1

Ramadhan, S., Sukma, E., \& Indriyani, V. (2019). Environmental education and disaster mitigation trough language learning. IOP Converence Series: Earth and Environmental Science, 314012054

Sari, Yuliana, Syahrul R, dan Yulianti Rasyid. (2018) Hubungan Antara Keterampilan Membaca dengan Keterampilan Menulis Teks Laporan Hasil Observasi Siswa Kelas X SMK Negeri 3 Padang. Jurnal Pendidikan Bahasa dan Sastra Indonesia. Vol. 7, No. 3

Suardi, Indah Permatasari, Syahrul R, dan Yasnur Asri (2019). Pemerolehan Bahasa Pertama Pada Anak Usia Dini. Jurnal Pendidikan Anak Usia DIni. Vol. 3, No. 1

Sukma, Elvia, S. Ramadhan dan V Indriyani. (2020). Integration of environmental education in elementary schools. Journal of Physic: Conference Series 1481

Sukma, Elvia, R. Mahyudin, Rahmatina dan A. Surian (2019). Problem in Oral Language Teaching In Primary School. Advance in Science, Education and Humanities Research. Vol. 301

Sukma, Elvia, Ritawati mahjuddin, dan Rizky Amelia. (2017). Literacy media Development in Improving Reading and Writing Skill of Early Class 
Students in Elementary School Padang Utara Padang. Advances in Science, Education and Humanities Research. Vol. 118 